\title{
Recombinant Granulocyte-Macrophage Colony-Stimulating Factor
}

National Cancer Institute

\section{Source}

National Cancer Institute. Recombinant Granulocyte-Macrophage Colony-Stimulating

Factor. NCI Thesaurus. Code C1288.

A recombinant therapeutic agent which is chemically identical to or similar to the endogenous glycoprotein cytokine growth factor granulocyte-macrophage colony stimulating factor (GM-CSF). Therapeutic GM-CSF induces the clonal expansion and differentiation of progenitor blood cells and stimulates the cytotoxicity of monocytes and neutrophils, thereby restoring immune function and host antitumor immune responses and stimulating eng raftment of transplanted bone marrow tissue. ( $\mathrm{NCl04)}$ 